\title{
Early cardiac remodeling in aortic coarctation: insights from fetal and neonatal functional and structural assessment
}

\author{
I. SOVERAL ${ }^{1}$ (D) F. CRISPI ${ }^{1,2,3}$, C. WALTER ${ }^{4}$, L. GUIRADO $^{1}$, P. GARCÍA-CANANALILA $^{5,6}$, \\ A. COOK $^{6}$, A. BONNIN ${ }^{7}$, H. DEJEA ${ }^{7,8}$, C. ROVIRA-ZURRIAGA ${ }^{9}$, J. SÁNCHEZ DE TOLEDO ${ }^{4}$, \\ E. GRATACÓS ${ }^{1,2,3}$, J. M. MARTÍNEZ ${ }^{1,2,3}$, B. BIJNENS ${ }^{5,10 \#}$ and O. GÓMEZ ${ }^{1,2,3 \#}$ \\ ${ }^{1}$ BCNatal-Barcelona Center for Maternal-Fetal and Neonatal Medicine (Hospital Clínic and Hospital Sant Joan de Déu), Barcelona, Spain; \\ ${ }^{2}$ Institut d'Investigacions Biomèdiques August Pi i Sunyer, Universitat de Barcelona, Barcelona, Spain; ${ }^{3}$ Centre for Biomedical Research on \\ Rare Diseases (CIBER-ER), Barcelona, Spain; ${ }^{4}$ Pediatric Cardiology, Hospital Sant Joan de Déu, Barcelona, Spain; ${ }^{5}$ PhySense, DTIC, \\ Universitat Pompen Fabra, Barcelona, Spain; ${ }^{6}$ Institute of Cardiovascular Science, University College London, London, UK; ${ }^{7}$ Swiss Light \\ Source, Paul Scherrer Institut, Villigen, Switzerland; ${ }^{8}$ Institute for Biomedical Engineering, ETH Zürich, Zürich, Switzerland; ${ }^{9}$ Department \\ of Pathology, Hospital Sant Joan de Déu, Barcelona, Spain; ${ }^{10}$ ICREA, Barcelona, Spain
}

KEYWORDS: aortic coarctation; echocardiography; fetal cardiac function; neonatal cardiac function; synchrotron tomography

\section{CONTRIBUTION}

What are the novel findings of this work?

This study provides a comprehensive assessment of biventricular morphometry and function in coarctation of the aorta $(\mathrm{COA})$ and offers new insights on cardiovascular adaptation as fetuses with CoA transition to the neonatal circulation.

What are the clinical implications of this work?

Our findings highlight the importance of the neonatal period as a critical time in which a previously normal functioning heart must rapidly accommodate a volume overload for which it seems poorly adapted. Thus, the neonatal period might provide an opportunity to deploy strategies that minimize adverse left ventricular remodeling.

\footnotetext{
ABSTRACT

Objectives Coarctation of the aorta (CoA) is associated with left ventricular $(L V)$ dysfunction in neonates and adults. Cardiac structure and function in fetal CoA and cardiac adaptation to early neonatal life have not been described. We aimed to investigate the presence of cardiovascular structural remodeling and dysfunction in fetuses with $\mathrm{CoA}$ and their early postnatal cardiac adaptation.
}

\begin{abstract}
Methods This was a prospective observational casecontrol study, conducted between 2011 and 2018 in a single tertiary referral center, of fetuses with CoA and gestational age-matched normal controls. All fetuses/neonates underwent comprehensive echocardiographic evaluation in the third trimester of pregnancy and after birth. Additionally, myocardial microstructure was assessed in one fetal and one neonatal CoA-affected heart specimen, using synchrotron radiation-based X-ray phase-contrast microcomputed tomography and histology, respectively.
\end{abstract}

Results We included 30 fetuses with $\mathrm{CoA}$ and 60 gestational age-matched controls. Of these, $20 \mathrm{CoA}$ neonates and 44 controls were also evaluated postnatally. Fetuses with CoA showed significant left-to-right volume redistribution, with right ventricular $(R V)$ size and output dominance and significant geometry alterations with an abnormally elongated $L V$, compared with controls ( $L V$ midventricular sphericity index (median (interquartile range; IQR), $2.4(2.0-2.7)$ vs 1.8 (1.7-2.0); $\mathrm{P}<0.001)$. Biventricular function was preserved and no ventricular hypertrophy was observed. Synchrotron tomography and histological assessment revealed normal myocyte organization in the fetal and neonatal specimens, respectively. Postnatally, the $L V$ in $C o A$ cases showed prompt remodeling, becoming more globular ( $L V$ midventricular sphericity index (mean $\pm S D$ ), $1.5 \pm 0.3$ in $\mathrm{CoA}$ vs $1.8 \pm 0.2$ in controls; $\mathrm{P}<0.001)$ with preserved

Correspondence to: Dr F. Crispi, Fetal i+D Fetal Medicine Research Center, BCNatal-Barcelona Center for Maternal-Fetal and Neonatal Medicine (Hospital Clínic and Hospital Sant Joan de Déu), Sabino de Arana street 1, 08028, Barcelona, Spain (e-mail: fcrispi@gmail.com) \#B.B. and O.G. contributed equally to this study.

Accepted: 23 December 2019 
systolic and normalized output, but altered diastolic, parameters compared with controls ( $L V$ inflow peak velocity in early diastole (mean $\pm S D), 97.8 \pm 14.5$ vs $56.5 \pm 12.9 \mathrm{~cm} / \mathrm{s} ; \mathrm{LV}$ inflow peak velocity in atrial contraction (median (IQR), 70.5 (60.1-84.9) vs 47.0 (43.0-55.0) cm/s; LV peak myocardial velocity in atrial contraction (mean $\pm S D), 5.1 \pm 2.6$ vs $6.3 \pm 2.2 \mathrm{~cm} / \mathrm{s}$; $\mathrm{P}<0.05)$. The neonatal $R V$ showed increased longitudinal function in the presence of a patent arterial duct.

Conclusions Our results suggest unique fetal cardiac remodeling in $C o A$, in which the $L V$ stays smaller from the decreased growth stimulus of reduced volume load. Postnatally, the LV is acutely volume-loaded, resulting in an overall geometry change with higher filling velocities and preserved systolic function. These findings improve our understanding of the evolution of CoA from fetal to neonatal life. Copyright (c) 2020 ISUOG. Published by John Wiley \& Sons Ltd.

\section{INTRODUCTION}

Coarctation of the aorta (CoA) accounts for 6-8\% of congenital heart defects (CHD) and is defined as narrowing of the aortic isthmus and, to a variable degree, the aortic $\operatorname{arch}^{1}$. Advances in prenatal diagnosis have contributed to a significant reduction in neonatal morbidity and mortality associated with CoA in the last decades ${ }^{2}$. However, prenatal detection remains challenging as it relies on indirect signs of cardiovascular remodeling within the complexity of the fetal circulation ${ }^{3}$. Thus, most studies have focused on describing the right-heart dominance and identifying related parameters that improve diagnostic accuracy, but there is very little information on cardiac functional changes and it is not clear whether fetuses with CoA present intrinsic myocardial dysfunction ${ }^{4,5}$.

Cardiac remodeling manifests clinically as changes in size, mass, geometry and function of the heart in response to load or injury ${ }^{6}$. This process can lead to impaired cardiac relaxation and/or ejection ability, which translates into clinical or subclinical dysfunction. Cardiac structural remodeling and dysfunction have been described in a variety of prenatal conditions ${ }^{7-9}$, however, this information is scarce in fetuses with $\mathrm{CHD}^{10}$.

Such a comprehensive structural and functional evaluation in fetuses with CoA could improve prenatal diagnosis and counseling and our understanding of the neonatal biventricular response. In this regard, presurgical biventricular dysfunction has been described in neonates with CoA and an open arterial duct under prostaglandin- $\mathrm{E}_{1}$ (PGE1) perfusion ${ }^{11}$. Additionally, persistent left ventricular (LV) alterations ${ }^{12}$ and increased cardiovascular risk, regardless of the presence of hypertension ${ }^{13}$, have been reported in both children and adults with repaired CoA. Whether these alterations are present prenatally and result from abnormal fetal myocardial differentiation or are the result of postnatal cardiovascular remodeling remains to be clarified. Cardiac tissue microstructural analysis could shed light on this issue, but no data on myocardial microscopic characteristics of CoA have been reported in the human fetus. New techniques, such as synchrotron radiation-based X-ray phase-contrast microcomputed tomography (X-PCI), have shown promise in the assessment of the cardiac microstructure of the whole heart, without the limitations of classic histology ${ }^{14,15}$.

The aims of the present study were to investigate the presence of cardiovascular structural remodeling and dysfunction in fetuses with CoA and to describe early postnatal cardiac adaptation in these infants.

\section{METHODS}

\section{Study population}

This was a prospective observational case-control study, conducted between 2011 and 2018, in a tertiary referral center for fetal and pediatric CHD (Hospital Clinic and Hospital Sant Joan de Déu) in Barcelona, Spain. The study was approved by the institutional ethics committee and written informed consent was obtained from all patients. Cases were selected from fetuses with high echocardiographic suspicion of CoA (significant right dominance and aortic isthmus diameter $Z$-score less than $-2)^{3}$ evaluated in our center during the study period. Exclusion criteria included pre- or postnatal diagnosis of additional major cardiac malformations (including LV outflow tract obstruction or mitral valve disease within Shone complex), major extracardiac malformations and genetic anomalies. The presence of bicuspid aortic valve was not considered an exclusion criterion, unless it resulted in LV outflow obstruction, and neither was the presence of minor cardiovascular anomalies, including ventricular septal defects (VSD). Only fetuses with postnatal confirmation of CoA were included in the analysis.

For each case, we recruited two gestational age (GA)-matched controls among patients who visited our center for routine pregnancy ultrasound scans. Only singleton, uncomplicated spontaneously conceived pregnancies, without known maternal or gestational conditions potentially affecting cardiovascular remodeling, were selected. GA was calculated based on the crown-rump length obtained on first-trimester ultrasound ${ }^{16}$. Third-trimester (32-36 weeks' gestation) fetal echocardiography and measurements were performed by experienced fetal medicine specialists (I.S., L.G., F.C. and O.G.). Early neonatal (48-96 h after birth) echocardiography and measurements were performed by an experienced pediatric cardiologist (C.W.). To eliminate potential confounders, for both cases and controls, only term neonates ( $>37$ weeks) with complete echocardiographic assessment performed between 48-96h after birth, and prior to coarctation treatment, were included in the postnatal analysis. Additionally, for CoA cases, we chose to include only those receiving PGE1 treatment. No controls were treated with PGE1. 
Cardiac histopathology was assessed postmortem in one case, corresponding to a preterm $(32+4$ weeks $)$ newborn with CoA. Furthermore, the database of the Cardiac Archive at the Institute of Cardiovascular Science and Child Health, held under license by the UK Human Tissue Authority, was searched to find human whole fetal heart specimens with isolated CoA. Only one specimen with these characteristics was found, of a 19-week old fetus. We then searched the database for one normal whole heart specimen of similar gestational age. This pregnancy was terminated for social reasons and necropsy confirmed the absence of cardiac or extracardiac abnormalities. X-PCI was then performed on both 19-week human fetal heart specimens (one with CoA and one normal heart).

\section{Maternal and perinatal characteristics}

Maternal characteristics, comorbidities and gestational complications were obtained from patient interview and medical records. Standard obstetric ultrasound and fetal echocardiography were performed in the third trimester. Fetal ultrasound was performed according to recommended guidelines and included calculation of estimated fetal weight (EFW) and EFW centile, extracardiac and cardiac detailed examinations ${ }^{17}$ and measurement of umbilical artery and fetal middle cerebral artery pulsatility indices ${ }^{18}$. EFW was estimated according to Hadlock et al. ${ }^{19}$ and EFW centile was calculated using local reference curves ${ }^{20}$. Delivery characteristics included GA at delivery, mode of delivery, Apgar score, umbilical artery $\mathrm{pH}$, birth weight and birth-weight centile ${ }^{20}$. Data regarding additional minor cardiovascular anomalies, age at scan and admission to the neonatal intensive care were collected. For CoA cases, information on PGE1 treatment, type of surgery, age at surgery, hospitalization stay and postoperative complications was also obtained.

\section{Fetal echocardiography}

Fetal echocardiography was performed using a Siemens Sonoline Antares (Siemens Medical Systems, Malvern, PA, USA) with a curved-array $2-6-\mathrm{MHz}$ or $2-10-\mathrm{MHz}$ transducer. Fetal cardiac morphometric measurements included cardiac and thoracic areas, cardiac longitudinal and transverse diameters, right ventricular (RV) and LV diameters (longitudinal, atrioventricular valves (basal) and midtransverse) and septal- and ventricularwall thicknesses ${ }^{21}$. Cardiothoracic ratio, cardiac sphericity, right-to-left ratios and ventricular sphericity indices were calculated. Fetal cardiac morphometric measurements were obtained in a two-dimensional apical or basal four-chamber view at end diastole, unless otherwise specified. Cardiothoracic ratio was calculated as cardiac area divided by thoracic area ${ }^{22}$. Cardiac sphericity and ventricular sphericity indices were calculated by dividing the longitudinal by the transverse diameter. Atrial areas were measured at the end-systolic maximum distention point by manual area delineation. Ventricular dimensions (longitudinal, atrioventricular valves (basal) and midtransverse) were measured according to previously published guidelines ${ }^{23}$. Diameters of the pulmonary and aortic valves were measured during systole, as previously decribed $^{23}$. RV and LV end-diastolic septal and free-wall thicknesses were measured by M-mode in a transverse four-chamber view ${ }^{24}$. Right-to-left ratios were calculated as right measurements divided by left measurements.

Systolic function evaluation ${ }^{25}$ included heart rate (HR), $\mathrm{RV}$ fractional area change (FAC), right and left stroke volumes (SV), cardiac output (CO), LV shortening fraction (SF), tricuspid (T) and mitral (M) annular-plane systolic excursion (APSE), peak systolic myocardial velocities $\left(S^{\prime}\right)$ and ejection times. HR was calculated from the spectral Doppler of aortic and pulmonary flow, by averaging three cardiac cycles. RV areas were measured by manual delineation in an apical or basal four-chamber view at end-diastole and RV-FAC was calculated as ((end-diastolic RV area-end-systolic RV area)/end-diastolic RV area) $\times 100$. Aortic and pulmonary systolic waves were obtained with angles as close to $0^{\circ}$ as possible and velocity-time integrals were calculated by manual tracing of the spectral Doppler area under the curve. Then, left and right SV were calculated as $\pi / 4 \times(\text { aortic or pulmonary valve diameter })^{2} \times($ aortic or pulmonary artery systolic flow velocity-time integral $)^{25}$. $\mathrm{CO}$ was calculated as $\mathrm{SV} \times \mathrm{HR}^{25}$ and was further adjusted by $\mathrm{EFW}^{26}$. Left SF was calculated from the internal ventricular diameters obtained from a transverse four-chamber view by M-mode using the following equation ${ }^{24}$ : ((end-diastolic dimension - end-systolic dimension)/end-diastolic dimension) $\times 100$. TAPSE and MAPSE were assessed in an apical or basal four-chamber view, by applying M-mode to the annular tricuspid and mitral annulus, respectively ${ }^{27}$. Tissue Doppler imaging was used to measure $S^{\prime}$ at the mitral and tricuspid lateral annuli in an apical or basal four-chamber view ${ }^{28}$. RV and LV ejection times were measured from pulmonary and aortic spectral Doppler systolic flow, using valve clicks as landmarks. To account for HR differences between subjects, outflow timing measurements were normalized to the cardiac cycle duration and expressed as a percentage of the mean duration of three cardiac cycles.

Diastolic function ${ }^{25}$ assessment included: ventricular inflow peak velocities in early diastole (E) and atrial contraction (A); E/A ratio and ventricular inflow timings; peak myocardial velocity in early diastole $\left(\mathrm{E}^{\prime}\right)$ and atrial contraction $\left(\mathrm{A}^{\prime}\right)$; and early diastolic velocity ratio $\left(\mathrm{E} / \mathrm{E}^{\prime}\right)$. $\mathrm{RV}$ and LV filling was assessed in a basal or apical four-chamber view, by placing the pulsed-Doppler volume immediately below and in between the tricuspid and mitral valve leaflets, respectively ${ }^{29}$. E and A transvalvular filling velocities were measured and $\mathrm{E} / \mathrm{A}$ ratio calculated. RV and LV inflow duration were measured from E-wave onset to A-wave termination, normalized to the cardiac cycle duration and expressed as a percentage of the mean duration of three cardiac cycles. Tissue Doppler imaging was used at mitral and tricuspid lateral annuli, from an apical or basal four-chamber view, to record $\mathrm{E}^{\prime}$ and $\mathrm{A}^{\prime}$ myocardial velocities ${ }^{28}$ and $\mathrm{E} / \mathrm{E}^{\prime}$ ratio was calculated. Significant tricuspid regurgitation was defined as presence 
of a persistent, holosystolic, regurgitant jet reaching the atrial ceiling.

\section{Neonatal echocardiography}

Neonatal echocardiography was performed while the patient was resting quietly or was asleep, using a Philips iE33 xMatrix (Philips Healthcare, Andover, MA, USA) with a $2-10-\mathrm{MHz}$ phased-array transducer, following a standardized protocol ${ }^{30}$. Neonatal cardiac morphometric, systolic and diastolic function measurements were the same as those obtained in the fetus, except for RV wall thickness and FAC which were not obtained in the neonatal assessment.

\section{Synchrotron radiation-based phase-contrast computed tomography}

Detailed description of data acquisition using X-PCI is provided in Appendix S1. Briefly, three-dimensional datasets were obtained using a $20-\mathrm{keV}$ parallel synchrotron X-ray beam. The field of view was $13.03 \times 3.2 \mathrm{~mm}^{2}$ with isotropic pixel size of $5.81 \mu \mathrm{m}$ for the CoA heart and $14 \times 9.6 \mathrm{~mm}^{2}$ with isotropic pixel size of $3.2 \mu \mathrm{m}$ for the normal heart specimen. Helical angle $\left(\alpha_{\mathrm{H}}\right)$ was computed as the angle between the transverse plane and the vector projection to the local tangential plane of the cylindrical coordinate system of the heart.

\section{Histopathology study}

Cardiac histopathology was assessed according to the standardized institutional protocol. Following paraffin inclusion, representative ventricular cross-sections were stained using hematoxylin-eosin, Masson's trichrome and van Giesen stains and the slides were evaluated by an experienced pathologist (C.R.-Z.).

\section{Statistical analysis}

Data were analyzed using the IBM SPSS Statistics version 23 statistical package (IBM Corp., Armonk, NY, USA). Shapiro-Wilk test of normality was performed for continuous variables. Continuous variables are presented as median (interquartile range) or mean $\pm \mathrm{SD}$, as appropriate. Comparisons were performed using Student's $t$-test, Mann-Whitney U-test or Wilcoxon rank-sum test, as appropriate. Categorical variables are presented as $n$ $(\%)$ and differences between the groups were compared using chi-square test. $P<0.05$ was considered statistically significant. Case-control baseline characteristics were assessed to identify potential confounders, but no further adjustment was necessary. Bonferroni correction for multiple comparisons was applied.

\section{RESULTS}

During the study period, 78 fetuses with suspected CoA met the inclusion criteria, of which 11 opted for termination of pregnancy, 23 were excluded due to preor postnatal detection of additional major cardiac or extracardiac malformations or genetic abnormalities and one patient was lost to follow-up (Figure 1). Of the remaining 43 patients, CoA was confirmed postnatally in 30 and was ruled out in 13. All CoA cases born in our center during the study period had been identified prenatally and were included in this study. The fetal group consisted of 30 cases with postnatally confirmed CoA and 60 GA-matched controls.

Ten newborns with CoA and 16 controls in total were excluded from postnatal analysis due to prematurity (two cases and two controls), management without PGE1 (two cases) or because the echocardiographic assessment was incomplete or performed outside the 48-96-h timeframe (six cases and 14 controls). Therefore, postnatal echocardiographic findings were analyzed in 20 CoA cases and 44 controls (Figure 1). All CoA cases included in the postnatal analyses were assessed prior to coarctation treatment.

Baseline and perinatal characteristics of the prenatal cohort are shown in Table 1 . The two study groups were similar in terms of maternal age, GA at scan and EFW. Fetoplacental Doppler values were normal in both groups. GA at birth, birth weight, rate of vaginal delivery and rate of pregnancy complications, such as preterm birth, birth weight $<10^{\text {th }}$ centile and gestational diabetes, were similar between the two groups. No other pregnancy complications were observed. Low 5-min Apgar score was infrequent (2/30 of CoA cases and none in controls) and umbilical artery $\mathrm{pH}$ was normal and similar in the two groups. No controls were admitted to the neonatal intensive care unit (NICU).

\section{Fetal echocardiographic findings}

Fetal cardiac morphometric and functional characteristics are summarized in Table 2 and Table 3 . As expected, there was a right dominance in fetuses with CoA compared to controls, however, the dominance was mainly due to smaller left side structures, especially at midtransverse ventricular diameter. As the long-axis lengths were similar, CoA fetuses showed a more elongated LV (increased sphericity index) and a slightly more globular RV compared with controls (Table 2 and Figure 2). There was no myocardial hypertrophy on either ventricle. Additionally, fetuses with CoA had significantly smaller left atrial area and larger right atrial area compared with controls.

While these morphometric changes were associated with a redistribution of $\mathrm{SV}$ and $\mathrm{CO}$ in both ventricles (decreased in the LV and increased in the RV) in fetuses with CoA, systolic and diastolic functional parameters were preserved, with the exception of increased blood-pool filling velocities (E and A) in the LV and a slight increase in $\mathrm{LV}-\mathrm{E} / \mathrm{E}^{\prime}$ ratio. Subgroup analysis considering the presence of arch hypoplasia and type of surgical repair did not reveal a different morphometric or functional profile. Fetuses with CoA and VSD presented larger LVs with similar functional profile to those with intact septum, however, the largest filling velocities and $\mathrm{E} / \mathrm{E}^{\prime}$ were present in the VSD subgroup (Tables S1-S5). 


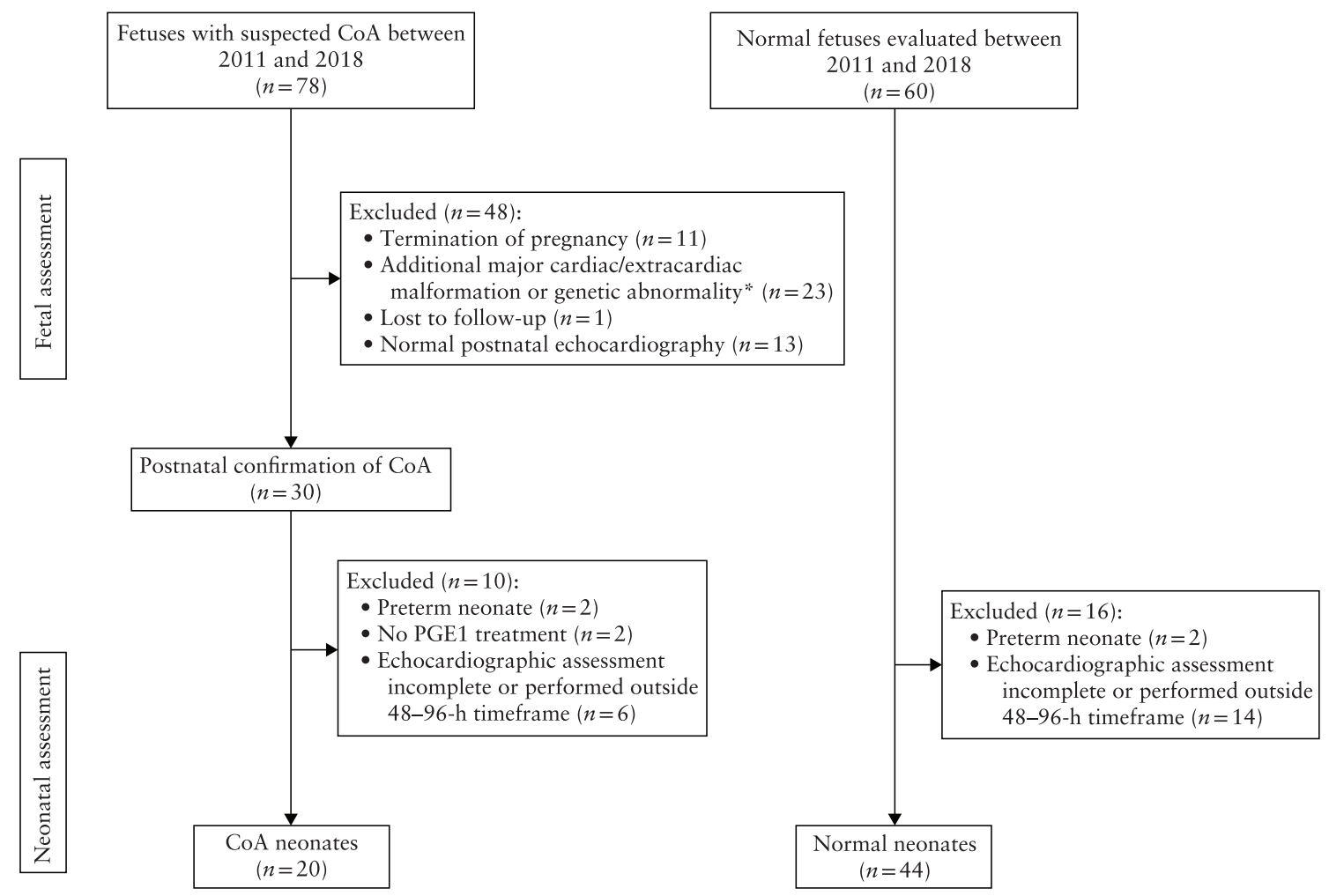

Figure 1 Flowchart showing inclusion in pre- and postnatal assessment of cases with coarctation of the aorta (CoA) and gestational agematched normal controls. "Diagnosed pre- or postnatally and including Shone complex. PGE1, prostaglandin-E 1 .

Table 1 Maternal and fetoplacental characteristics, delivery outcome and clinical management of 30 fetuses with postnatally confirmed aortic coarctation $(\mathrm{CoA})$ and 60 gestational age-matched normal controls

\begin{tabular}{|c|c|c|c|}
\hline Parameter & $\operatorname{CoA}(\mathrm{n}=30)$ & Controls $(\mathrm{n}=60)$ & $\mathrm{P}$ \\
\hline \multicolumn{4}{|l|}{ Maternal and fetoplacental characteristics } \\
\hline Maternal age (years) & $34.0 \pm 5.5$ & $32.1 \pm 5.4$ & 0.169 \\
\hline Gestational age at scan (weeks) & $32.7 \pm 3.6$ & $32.6 \pm 3.2$ & 0.915 \\
\hline Estimated fetal weight (g) & $2097 \pm 771$ & $2114 \pm 684$ & 0.919 \\
\hline Estimated fetal-weight centile & $62 \pm 33$ & $55 \pm 28$ & 0.266 \\
\hline Estimated fetal weight $<10^{\text {th }}$ centile & $2(6.7)$ & $2(3.3)$ & 0.603 \\
\hline Umbilical artery pulsatility index & $1.06 \pm 0.19$ & $1.01 \pm 0.19$ & 0.329 \\
\hline Middle cerebral artery pulsatility index & $1.82 \pm 0.35$ & $1.99 \pm 0.40$ & 0.064 \\
\hline Cerebroplacental ratio & $1.76 \pm 0.39$ & $2.07 \pm 0.54$ & 0.011 \\
\hline Cerebroplacental ratio $<5^{\text {th }}$ centile & $4(13.3)$ & $3(5.0)$ & 0.213 \\
\hline \multicolumn{4}{|l|}{ Delivery outcome } \\
\hline Vaginal delivery & $24(80.0)$ & $52(86.7)$ & 0.508 \\
\hline Gestational age at delivery (weeks) & $39.7(37.9-40.0)$ & $39.9(38.1-40.7)$ & 0.107 \\
\hline Spontaneous preterm birth < 37 weeks & $2(6.7)$ & $2(3.3)$ & 1.000 \\
\hline Birth weight (g) & $3140 \pm 685$ & $3215 \pm 425$ & 0.592 \\
\hline Birth weight $<10^{\text {th }}$ centile & $4(13.3)$ & $6(10.0)$ & 0.740 \\
\hline 5-min Apgar score $<7$ & $2(6.7)$ & $0(0)$ & 0.119 \\
\hline Umbilical artery $\mathrm{pH}$ & $7.25 \pm 0.07$ & $7.24 \pm 0.06$ & 0.260 \\
\hline \multicolumn{4}{|l|}{ Clinical management of CoA } \\
\hline Admission to NICU & $27(90.0)$ & - & - \\
\hline Treatment with PGE1 & $26(86.7)$ & - & - \\
\hline Age at surgery (days) & $8.9 \pm 5.8$ & - & - \\
\hline Length of hospital stay (days) & $33.6 \pm 16.2$ & - & - \\
\hline Major neonatal morbidity & $7(23.3)$ & - & - \\
\hline Primary angioplasty & $4(13.3)$ & - & - \\
\hline Terminoterminal coarctectomy & $7(23.3)$ & - & - \\
\hline Extended arch repair & $19(63.3)$ & - & - \\
\hline
\end{tabular}

Data are given as mean $\pm \mathrm{SD}$, median (interquartile range) or $n(\%)$. NICU, neonatal intensive care unit; PGE1, prostaglandin- $\mathrm{E}_{1}$. 
Table 2 Fetal morphometric echocardiographic findings in 30 fetuses with postnatally confirmed aortic coarctation (CoA) and 60 gestational age-matched normal controls

\begin{tabular}{|c|c|c|c|}
\hline Parameter & $\operatorname{CoA}(\mathrm{n}=30)$ & Controls $(\mathrm{n}=60)$ & $\mathrm{P}$ \\
\hline Gestational age at scan (weeks) & $34.0 \pm 5.5$ & $32.1 \pm 5.4$ & 0.915 \\
\hline \multicolumn{4}{|l|}{ Cardiac dimensions } \\
\hline Cardiac area $\left(\mathrm{cm}^{2}\right)$ & $11.2 \pm 3.3$ & $11.6 \pm 3.3$ & 0.639 \\
\hline Cardiac longitudinal diameter (mm) & $38.8 \pm 7.0$ & $41.2 \pm 6.7$ & 0.149 \\
\hline Cardiac transverse diameter (mm) & $33.7 \pm 5.3$ & $35.1 \pm 5.3$ & 0.279 \\
\hline Cardiothoracic ratio* & $0.28 \pm 0.04$ & $0.28 \pm 0.04$ & 0.528 \\
\hline Cardiac sphericity $\dagger$ & $1.2 \pm 0.2$ & $1.2 \pm 0.1$ & 0.612 \\
\hline \multicolumn{4}{|l|}{ Right-to-left dimensions } \\
\hline Tricuspid/mitral valve ratio & $1.5(1.4-1.8)$ & $1.0(0.9-1.1)$ & $<0.001$ \\
\hline RV/LV midtransverse diameter ratio & $1.6(1.4-2.1)$ & $1.1(0.9-1.2)$ & $<0.001$ \\
\hline RV/LV longitudinal diameter ratio & $1.1(1.0-1.2)$ & $0.96(0.86-1.0)$ & 0.001 \\
\hline Pulmonary/aortic valve ratio & $1.9 \pm 0.3$ & $1.1 \pm 0.2$ & $<0.001$ \\
\hline Right/left atrial area ratio & $1.7(1.4-2.1)$ & $1.1(1.0-1.2)$ & $<0.001$ \\
\hline RV/LV stroke volume ratio & $3.6(2.7-4.6)$ & $1.2(0.9-1.5)$ & $<0.001$ \\
\hline RV/LV wall thickness ratio & $1.0(0.9-1.2)$ & $1.0(0.9-1.1)$ & 0.233 \\
\hline \multicolumn{4}{|l|}{ Right atrial and ventricular dimensions } \\
\hline Right atrial area $\left(\mathrm{cm}^{2}\right)$ & $2.4(1.7-3.0)$ & $1.8(1.4-2.5)$ & 0.037 \\
\hline RV longitudinal diameter (mm) & $21.9 \pm 4.2$ & $20.6 \pm 4.3$ & 0.177 \\
\hline RV longitudinal diameter $Z$-score & $0.30 \pm 0.92$ & $-0.11 \pm 0.97$ & 0.068 \\
\hline Tricuspid annulus diameter (mm) & $13.4 \pm 2.2$ & $12.7 \pm 2.5$ & 0.262 \\
\hline Tricuspid annulus diameter $Z$-score & $0.05 \pm 1.1$ & $-0.35 \pm 1.0$ & 0.085 \\
\hline RV midtransverse diameter (mm) & $13.4(12.3-17.0)$ & $12.8(11.0-14.8)$ & $<0.001$ \\
\hline $\mathrm{RV}$ midtransverse diameter $Z$-score & $1.3(0.21-1.9)$ & $0.28(-0.71$ to 0.75$)$ & $<0.001$ \\
\hline Pulmonary valve diameter (mm) & $8.7 \pm 1.8$ & $6.5 \pm 1.3$ & $<0.001$ \\
\hline Pulmonary valve diameter $Z$-score & $1.8 \pm 1.4$ & $-0.38 \pm 1.3$ & $<0.001$ \\
\hline RV basal sphericity index $\ddagger$ & $1.6 \pm 0.2$ & $1.7 \pm 0.3$ & 0.062 \\
\hline RV midventricular sphericity index $\ddagger$ & $1.4 \pm 0.2$ & $1.7 \pm 0.3$ & 0.001 \\
\hline \multicolumn{4}{|l|}{ Left atrial and ventricular dimensions } \\
\hline Left atrial area $\left(\mathrm{cm}^{2}\right)$ & $1.3(1.1-1.7)$ & $1.7(1.3-2.1)$ & 0.017 \\
\hline LV longitudinal diameter $(\mathrm{mm})$ & $20.1 \pm 4.2$ & $21.8 \pm 4.7$ & 0.438 \\
\hline LV longitudinal diameter $Z$-score & $-0.8 \pm 1.0$ & $-0.5 \pm 1.2$ & 0.426 \\
\hline Mitral annulus diameter (mm) & $8.7(7.7-9.9)$ & $11.9(11.0-14.3)$ & $<0.001$ \\
\hline Mitral annulus diameter $Z$-score & $-2.5(-2.9$ to -1.7$)$ & $-0.12(-0.95$ to 0.45$)$ & $<0.001$ \\
\hline LV midtransverse diameter (mm) & $8.8 \pm 2.5$ & $12.0 \pm 2.8$ & $<0.001$ \\
\hline LV midtransverse diameter $Z$-score & $-1.79 \pm 1.18$ & $-0.17 \pm 0.91$ & $<0.001$ \\
\hline Aortic valve diameter $(\mathrm{mm})$ & $4.6 \pm 0.9$ & $5.8 \pm 1.1$ & $<0.001$ \\
\hline Aortic valve diameter $Z$-score & $-1.2(-1.9$ to -0.6$)$ & $0.4(-0.5$ to 1.4$)$ & $<0.001$ \\
\hline LV basal sphericity index $\neq$ & $2.4(2.0-2.8)$ & $1.8(1.5-2.0)$ & $<0.001$ \\
\hline LV midventricular sphericity indexł & $2.4(2.0-2.7)$ & $1.8(1.7-2.0)$ & $<0.001$ \\
\hline \multicolumn{4}{|l|}{ Myocardial wall thickness } \\
\hline RV free-wall thickness (mm) & $3.1(2.8-3.8)$ & $3.5(3.0-4.2)$ & 0.144 \\
\hline LV free-wall thickness (mm) & $3.0(2.6-3.6)$ & $3.3(3.0-4.2)$ & 0.010 \\
\hline Septal-wall thickness (mm) & $3.7 \pm 0.9$ & $3.5 \pm 0.7$ & 0.111 \\
\hline
\end{tabular}

Data are given as mean \pm SD or median (interquartile range). *Calculated as cardiac/thoracic area. $†$ Calculated as longitudinal/transverse cardiac diameter. $\ddagger$ Basal sphericity index calculated as longitudinal/transverse diameter at atrioventricular valves and midventricular sphericity index calculated as longitudinal/transverse diameter at midventricular level. LV, left ventricle; RV, right ventricle.

\section{Postnatal evolution of CoA cases}

Postnatal evolution of the 30 fetuses with CoA is summarized in Table 1. Clinical management was decided in multidisciplinary sessions, including neonatologists, pediatric cardiologists, cardiac surgeons and anesthesiologists, and was based on the best available clinical evidence considering the characteristics of the individual patient and the available resources. Twenty-seven $(90 \%)$ patients were admitted to the neonatal intensive care unit and PGE1 treatment was started in 26 patients $(86.7 \%)$. Four patients were treated with primary angioplasty, including three patients managed without PGE1 perfusion. Surgery was performed in the remaining 26 patients, with a median age of 8 (range, 2-30) days. Terminoterminal coarctectomy was performed in seven cases, while 19 newborns required extended arch repair. Surgical VSD closure was considered necessary in 4/13 patients with VSD. Median age at discharge was 26 (range, 9-103) days. Major neonatal morbidity was present in $23.3 \%$ of cases and included pneumothorax after chest tube removal, sepsis of abdominal origin, necrotizing enterocolitis and diaphragmatic paralysis.

All 20 cases that were included in postnatal analysis were admitted to the NICU and PGE1 treatment was started. Terminoterminal coarctectomy was performed in 
Table 3 Fetal functional echocardiographic findings in 30 fetuses with postnatally confirmed aortic coarctation (CoA) and 60 gestational age-matched normal controls

\begin{tabular}{|c|c|c|c|}
\hline Parameter & $\operatorname{CoA}(\mathrm{n}=30)$ & Controls $(\mathrm{n}=60)$ & $\mathrm{P}$ \\
\hline Gestational age at scan (weeks) & $34.0 \pm 5.5$ & $32.1 \pm 5.4$ & 0.915 \\
\hline Heart rate (bpm) & $137 \pm 11$ & $139 \pm 11$ & 0.567 \\
\hline Combined cardiac output $(\mathrm{mL} / \mathrm{min} / \mathrm{kg})$ & $501(403-608)$ & $441(343-487)$ & 0.040 \\
\hline \multicolumn{4}{|l|}{ Right ventricular function } \\
\hline Fractional area change $(\%)$ & $28.5 \pm 12.2$ & $28.1 \pm 10.2$ & 0.855 \\
\hline Stroke volume $(\mathrm{mL})$ & $5.3(3.7-8.3)$ & $3.0(2.2-4.4)$ & $<0.001$ \\
\hline Cardiac output (L/min) & $0.8(0.5-1.1)$ & $0.5(0.3-0.6)$ & $<0.001$ \\
\hline Cardiac output adjusted by EFW (mL/min/kg) & $371(320-463)$ & $230(168-282)$ & $<0.001$ \\
\hline TAPSE $(\mathrm{mm})$ & $7.83 \pm 1.8$ & $7.3 \pm 1.6$ & 0.200 \\
\hline $\mathrm{S}^{\prime}(\mathrm{cm} / \mathrm{s})$ & $7.9 \pm 1.2$ & $7.7 \pm 1.1$ & 0.275 \\
\hline Right ejection time (\%) & $43.6 \pm 8.2$ & $43.3 \pm 3.1$ & 0.878 \\
\hline $\mathrm{E}(\mathrm{cm} / \mathrm{s})$ & $44.1(36.7-48.8)$ & $42.9(36.7-48.8)$ & 0.984 \\
\hline $\mathrm{A}(\mathrm{cm} / \mathrm{s})$ & $59.3 \pm 11.5$ & $56.4 \pm 9.6$ & 0.250 \\
\hline E/A ratio & $0.7(0.7-0.8)$ & $0.8(0.7-0.8)$ & 0.734 \\
\hline Tricuspid inflow time $(\%)$ & $40.5 \pm 3.0$ & $40.7 \pm 5.2$ & 0.840 \\
\hline $\mathrm{E}^{\prime}(\mathrm{cm} / \mathrm{s})$ & $8.9 \pm 2.4$ & $8.1 \pm 1.5$ & 0.114 \\
\hline $\mathrm{A}^{\prime}(\mathrm{cm} / \mathrm{s})$ & $11.9 \pm 2.0$ & $10.9 \pm 1.9$ & 0.078 \\
\hline $\mathrm{E} / \mathrm{E}^{\prime}$ ratio & $5.2(4.6-6.1)$ & $5.2(4.7-6.4)$ & 0.552 \\
\hline Significant tricuspid regurgitation & $1(3.3)$ & $0(0)$ & 0.659 \\
\hline \multicolumn{4}{|l|}{ Left ventricular function } \\
\hline Stroke volume $(\mathrm{mL})$ & $1.8(1.2-2.1)$ & $2.6(1.8-4.2)$ & $<0.001$ \\
\hline Cardiac output (L/min) & $0.2(0.1-0.3)$ & $0.4(0.3-0.5)$ & $<0.001$ \\
\hline Cardiac output adjusted by EFW (mL/min/kg) & $107(90-141)$ & $192(138-233)$ & $<0.001$ \\
\hline Shortening fraction $(\%)$ & $39.8 \pm 11.0$ & $35.2 \pm 12.1$ & 0.128 \\
\hline Ejection fraction $(\%)$ & $68.5 \pm 13.0$ & $62.6 \pm 12.1$ & 0.064 \\
\hline MAPSE (mm) & $5.0(4.1-5.6)$ & $5.0(4.3-5.8)$ & 0.968 \\
\hline $\mathrm{S}^{\prime}(\mathrm{cm} / \mathrm{s})$ & $7.0 \pm 1.4$ & $6.9 \pm 1.3$ & 0.751 \\
\hline Left ejection time (\%) & $40.7(38.7-43.3)$ & $41.2(39.1-43.5)$ & 0.667 \\
\hline Isovolumetric contraction time (ms) & $40.0(29.5-47.0)$ & $35.0(33.0-40.0)$ & 0.367 \\
\hline Isovolumetric relaxation time (ms) & $52.0(50.0-57.0)$ & $50.0(44.0-54.0)$ & 0.104 \\
\hline $\mathrm{E}(\mathrm{cm} / \mathrm{s})$ & $43.0(37.2-49.5)$ & $36.6(32.0-43.0)$ & 0.009 \\
\hline $\mathrm{A}(\mathrm{cm} / \mathrm{s})$ & $56.6(47.3-64.0)$ & $46.8(43.5-53.3)$ & 0.001 \\
\hline E/A ratio & $0.8(0.7-0.9)$ & $0.8(0.7-0.9)$ & 0.325 \\
\hline Mitral inflow time (\%) & $43.1 \pm 4.6$ & $43.2 \pm 5.1$ & 0.946 \\
\hline $\mathrm{E}^{\prime}(\mathrm{cm} / \mathrm{s})$ & $7.0 \pm 1.1$ & $7.3 \pm 1.3$ & 0.329 \\
\hline $\mathrm{A}^{\prime}(\mathrm{cm} / \mathrm{s})$ & $9.4 \pm 2.0$ & $9.7 \pm 2.4$ & 0.651 \\
\hline $\mathrm{E} / \mathrm{E}^{\prime}$ ratio & $6.3(5.1-7.2)$ & $5.4(4.2-6.3)$ & 0.026 \\
\hline
\end{tabular}

Data are given as mean $\pm \mathrm{SD}$, median (interquartile range) or $n(\%)$. A, ventricular inflow peak velocity in atrial contraction; $\mathrm{A}^{\prime}$, peak myocardial velocity in atrial contraction; bpm, beats per min; E, ventricular inflow peak velocity in early diastole; $\mathrm{E}^{\prime}$, peak myocardial velocity in early diastole; EFW, estimated fetal weight; MAPSE, mitral annular plane systolic excursion; $\mathrm{S}^{\prime}$, peak systolic myocardial velocity; TAPSE, tricuspid annular plane systolic excursion.

five of the cases and 15 newborns required extended arch repair. The group of neonates in the postnatal analysis included five patients with a VSD, of which one required surgical closure.

Cardiac histopathological study was performed in the only neonatal death that occurred in this fetal study group. The patient was born at $32+4$ weeks and died at 33 days of age, following coarctectomy at 14 days and clinical recoarctation that required angioplasty on the $27^{\text {th }}$ day. This procedure was complicated by aneurysm development and rupture, which resulted in massive hemothorax and death. The patient also presented an atrial septal defect with persistent left-to-right shunt, leading to progressive right cardiac dilatation, pulmonary hypertension and reduced LV filling. This case was not included in the postnatal echocardiographic analysis due to extreme prematurity.

\section{Neonatal echocardiographic findings}

Neonatal cardiac morphometric and functional characteristics are summarized in Table 4 and Table 5. Similar to the prenatal findings, newborns with CoA under PGE1 perfusion showed larger right-to-left ratios compared with controls, however, the ventricular disproportion was less apparent and the differences were not statistically significant at the midventricular level. The RV diameters and shape were similar between neonates with CoA and controls. Interestingly, the LV transverse diameter in neonates with CoA was similar to that in controls, and given a shorter length, the LV became significantly more globular in CoA cases (with lower midventricular sphericity index). Additionally, and unlike in fetal life, the left atria were significantly enlarged in CoA cases compared to controls. 
(a)
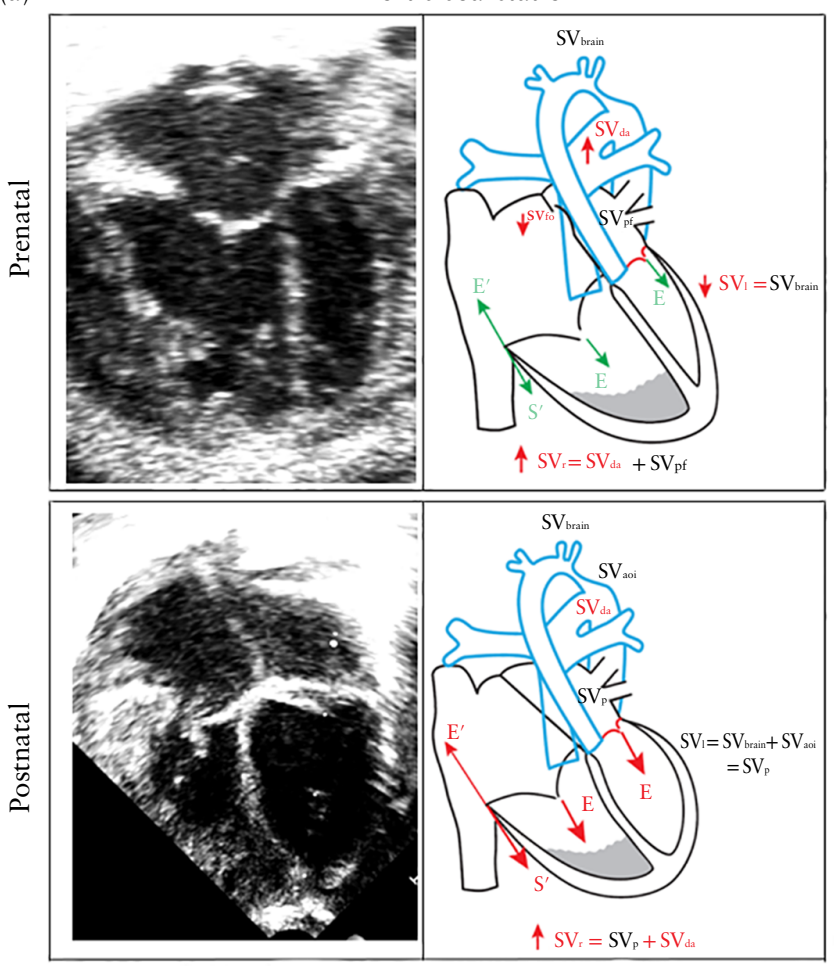

(b)
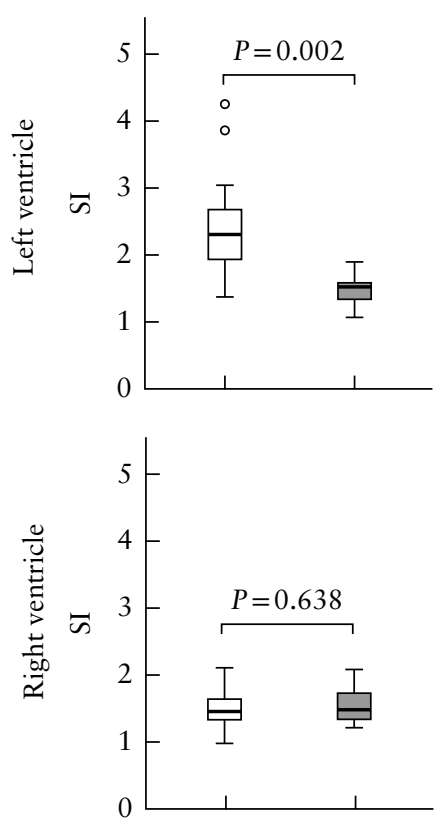

Aortic coarctation
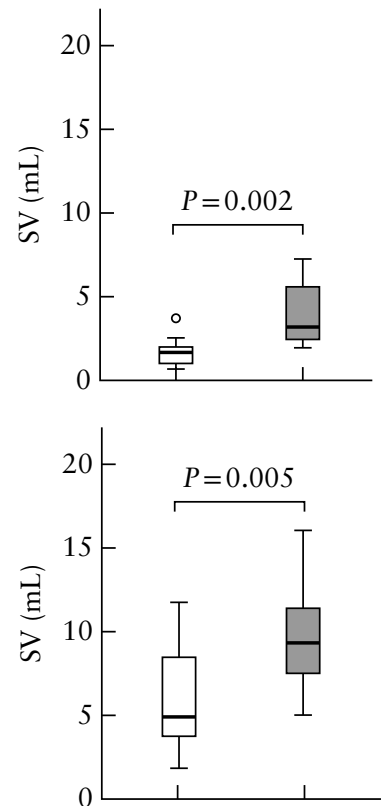

Control
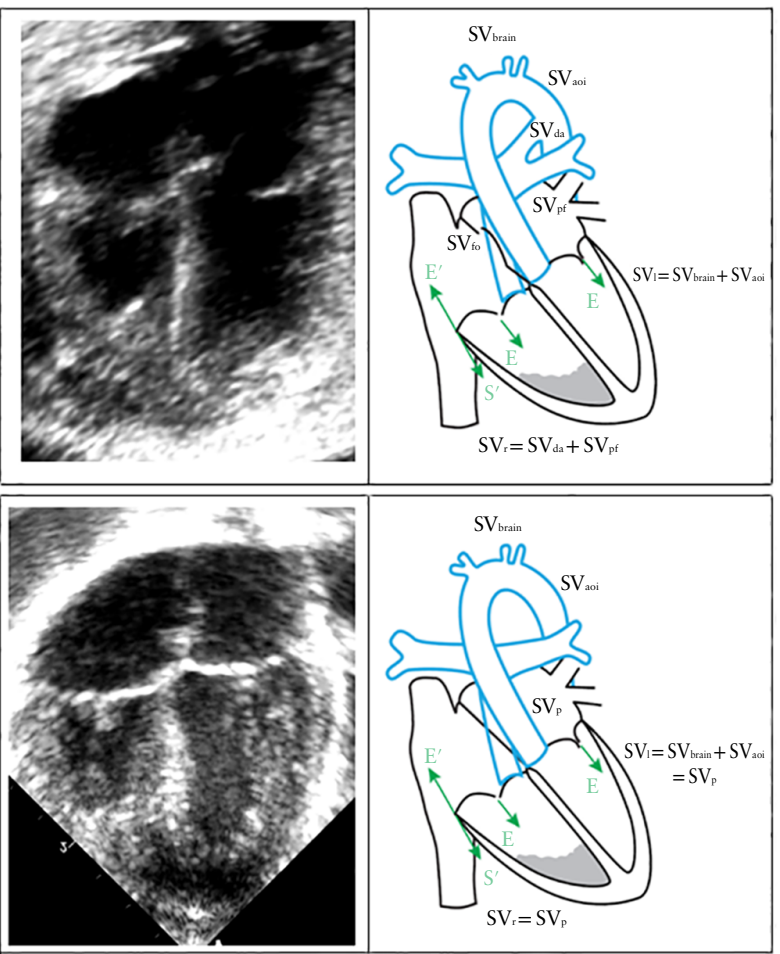

Control
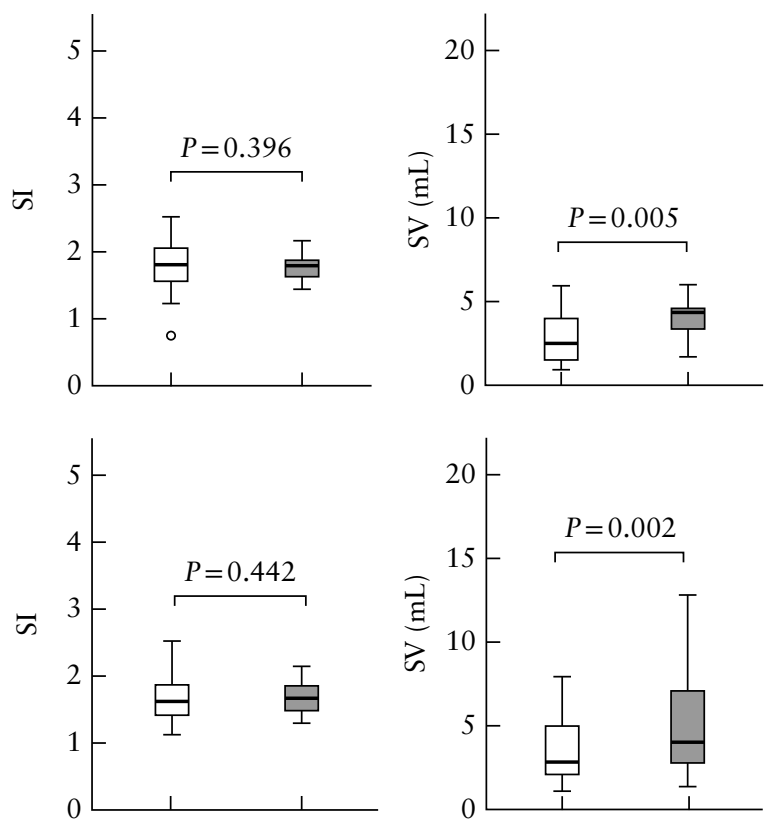

Figure 2 Prenatal and postnatal morphological and functional echocardiographic findings in cases with aortic coarctation $(\mathrm{CoA})$ and gestational age-matched normal controls. (a) Pre- and postnatal four-chamber view and respective cardiac representation in CoA cases and controls. Smaller left atrium and smaller and more elongated left ventricle can be seen in four-chamber view in fetal CoA, while globular shape is seen in four-chamber view in neonatal CoA. Blood flow redistribution in fetal CoA compared with controls and cardiovascular adaptation to neonatal life are shown for cases of pre- and postnatal CoA and controls. (b) Box-and-whiskers plots showing prenatal ( $\square$ ) and postnatal ( $\square$ ) left and right midventricular sphericity index (SI) and stroke volume (SV) in CoA cases and controls. SI calculated as longitudinal/midventricular diameter. Boxes are median and interquartile range (IQR), whiskers are range, excluding outliers more than $1.5 \times$ IQR from upper or lower quartile, and circles are outliers. E, ventricular inflow peak velocity in early diastole; $\mathrm{E}^{\prime}$, peak myocardial velocity in early diastole; $\mathrm{S}^{\prime}$, peak systolic myocardial velocity; $\mathrm{SV}_{\text {aoi }}$, stroke volume through aortic isthmus; $\mathrm{SV}_{\text {brain }}$, stroke volume to brain; $\mathrm{SV}_{\mathrm{da}}$, stroke volume through ductus arteriosus; $\mathrm{SV}_{\mathrm{fo}}$, stroke volume through foramen ovale; $\mathrm{SV}_{1}$, stroke volume left ventricle; $\mathrm{SV}_{\mathrm{p}}$, neonatal pulmonary stroke volume; $\mathrm{SV}_{\mathrm{pf}}$, fetal pulmonary stroke volume; $\mathrm{SV}_{\mathrm{r}}$, stroke volume right ventricle. 
Table 4 Neonatal morphometric echocardiographic findings in 20 neonates with aortic coarctation (CoA) and 44 gestational age-matched normal controls

\begin{tabular}{|c|c|c|c|}
\hline Parameter & $\operatorname{CoA}(\mathrm{n}=20)$ & Controls $(\mathrm{n}=44)$ & $\mathrm{P}$ \\
\hline Age at scan (days) & $3.0(2.0-3.0)$ & $2.0(2.0-2.8)$ & 0.283 \\
\hline \multicolumn{4}{|l|}{ Right-to-left dimensions } \\
\hline Tricuspid/mitral valve ratio & $1.2 \pm 0.2$ & $1.0 \pm 0.2$ & 0.137 \\
\hline RV/LV midtransverse diameter ratio & $0.9 \pm 0.2$ & $0.9 \pm 0.2$ & 0.837 \\
\hline RV/LV longitudinal diameter ratio & $0.9 \pm 0.2$ & $0.8 \pm 0.1$ & 0.013 \\
\hline Pulmonary/aortic valve ratio & $1.6 \pm 0.4$ & $1.1 \pm 0.2$ & $<0.001$ \\
\hline Right/left atrial area ratio & $1.1(1.0-1.3)$ & $1.1(1.0-1.2)$ & 0.848 \\
\hline RV/LV stroke volume ratio & $2.4(1.8-4.8)$ & $1.4(0.7-2.0)$ & 0.002 \\
\hline \multicolumn{4}{|l|}{ Right atrial and ventricular dimensions } \\
\hline Right atrial area $\left(\mathrm{cm}^{2}\right)$ & $2.6(2.0-3.0)$ & $2.1(1.9-2.3)$ & 0.010 \\
\hline $\mathrm{RV}$ longitudinal diameter (mm) & $24.3 \pm 6.7$ & $23.6 \pm 2.5$ & 0.507 \\
\hline Tricuspid annulus diameter (mm) & $11.1 \pm 1.9$ & $11.6 \pm 1.6$ & 0.471 \\
\hline $\mathrm{RV}$ midtransverse diameter ( $\mathrm{mm})$ & $15.5 \pm 2.6$ & $14.4 \pm 2.0$ & 0.205 \\
\hline Pulmonary valve diameter (mm) & $9.8 \pm 1.5$ & $7.3 \pm 1.4$ & $<0.001$ \\
\hline RV basal sphericity index* & $2.0 \pm 0.4$ & $2.1 \pm 0.3$ & 0.330 \\
\hline RV midventricular sphericity index* & $1.5 \pm 0.2$ & $1.7 \pm 0.2$ & 0.434 \\
\hline \multicolumn{4}{|l|}{ Left atrial and ventricular dimensions } \\
\hline Left atrial area $\left(\mathrm{cm}^{2}\right)$ & $2.4 \pm 0.5$ & $2.1 \pm 0.4$ & 0.005 \\
\hline LV longitudinal diameter $(\mathrm{mm})$ & $25.7 \pm 4.9$ & $27.8 \pm 2.5$ & 0.074 \\
\hline Mitral annulus diameter (mm) & $10.0(8.6-11.0)$ & $11.5(10.3-12.0)$ & 0.001 \\
\hline LV midtransverse diameter (mm) & $16.0(15.0-18.5)$ & $16.0(14.3-17.0)$ & 0.649 \\
\hline Aortic valve diameter $(\mathrm{mm})$ & $5.9(5.5-6.7)$ & $7.0(6.0-7.0)$ & 0.003 \\
\hline LV basal sphericity index* & $2.4 \pm 0.4$ & $2.5 \pm 0.3$ & 0.203 \\
\hline LV midventricular sphericity index* & $1.5 \pm 0.3$ & $1.8 \pm 0.2$ & $<0.001$ \\
\hline \multicolumn{4}{|l|}{ Wall thickness } \\
\hline LV free-wall thickness (mm) & $3.8(3.0-4.2)$ & $3.0(3.0-3.0)$ & 0.003 \\
\hline Septal-wall thickness (mm) & $4.0(3.1-4.6)$ & $3.0(3.0-3.0)$ & 0.001 \\
\hline \multicolumn{4}{|l|}{ Additional findings } \\
\hline Hypoplastic aortic arch & $10(50)$ & $0(0)$ & $<0.001$ \\
\hline Bicuspid aortic valve & $8(40)$ & $0(0)$ & $<0.001$ \\
\hline Ventricular septal defect & $5(25)$ & $0(0)$ & $<0.001$ \\
\hline Permeable foramen ovale at scan & $4(20)$ & $9(21)$ & 0.701 \\
\hline
\end{tabular}

Data are given as mean $\pm \mathrm{SD}$, median (interquartile range) or $n(\%)$. "Basal sphericity index calculated as longitudinal/transverse diameter at atrioventricular valves and midventricular sphericity index calculated as longitudinal/transverse diameter at midventricular level. LV, left ventricle; RV, right ventricle.

After birth, LV-CO and LV-SV increased in CoA cases, reaching values similar to those in controls (Table 5 and Figure 2), while MAPSE and S' remained similar between the two groups. Compared with controls, LV filling blood-pool velocities ( $\mathrm{E}$ and $\mathrm{A}$ ) were significantly higher in CoA cases and LV-E' was similar, which translated into a significantly higher $\mathrm{LV}-\mathrm{E} / \mathrm{E}^{\prime}$ ratio in neonates with CoA. Additionally, LV-A' was significantly lower in CoA neonates (Table 5).

$\mathrm{RV}-\mathrm{SV}$ and RV-CO remained higher in CoA newborns, as did the combined cardiac output, which was associated with significantly higher RV early filling velocities (E) and longitudinal systolic and diastolic motion, as shown by increased peak annular velocities $\left(\mathrm{E}^{\prime}, \mathrm{A}^{\prime}\right.$ and $\left.\mathrm{S}^{\prime}\right)$, compared with controls (Table 5).

\section{Myocyte orientation analysis and cardiac histopathology}

Figure 3 illustrates the results of the myocyte aggregates orientation analysis performed in the two X-PCI datasets. The architecture of LV myocardium in the two hearts analyzed (one normal and one with CoA) showed the typical gradual change of $\alpha_{\mathrm{H}}$ from epi- to endocardium, with longitudinally aligned fibers $\left(\alpha_{\mathrm{H}}, \sim-60^{\circ}\right)$ in the epicardium, more circumferential fibers $\left(\alpha_{\mathrm{H}}, \sim 0^{\circ}\right)$ in the mid-wall and longitudinal fibers $\left(\alpha_{\mathrm{H}}, \sim+60^{\circ}\right)$ in the endocardium, as have been described in the normal adult heart ${ }^{31}$, with no evidence of orientation remodeling, myocardial disorganization or fibrosis in the CoA specimen. Similarly, the cardiac histopathology of the preterm neonate with CoA showed no evidence of myocardial abnormalities or fibrosis (Figure 4).

\section{DISCUSSION}

We provide a comprehensive assessment of biventricular morphometry and function in CoA, from fetal to early neonatal life. Fetuses with CoA showed significant left-to-right volume redistribution with RV size and output dominance, and significant geometry alterations, with an abnormally elongated LV (increased sphericity) and preserved biventricular function and myocardial thickness. Our findings suggest unique fetal cardiac remodeling in CoA, in which prenatal volume redistribution prevents LV pressure increase. Postnatally, the LV is acutely 
Table 5 Neonatal functional echocardiographic findings in 20 neonates with aortic coarctation (CoA) and 44 gestational age-matched normal controls

\begin{tabular}{|c|c|c|c|}
\hline Parameter & $\operatorname{CoA}(\mathrm{n}=20)$ & Controls $(\mathrm{n}=44)$ & $P$ \\
\hline Age at scan (days) & $3.0(2.0-3.0)$ & $2.0(2.0-2.8)$ & 0.283 \\
\hline Heart rate (bpm) & $137 \pm 16$ & $127 \pm 16$ & 0.036 \\
\hline Combined cardiac output (mL/min/kg) & $603 \pm 197$ & $372 \pm 131$ & 0.001 \\
\hline \multicolumn{4}{|l|}{ Right ventricular function } \\
\hline Stroke volume $(\mathrm{mL})$ & $9.4(6.2-11.6)$ & $4.0(2.8-7.3)$ & 0.001 \\
\hline Cardiac output (L/min) & $1.3(0.8-1.6)$ & $0.5(0.4-1.0)$ & 0.003 \\
\hline Cardiac output adjusted by weight $(\mathrm{mL} / \mathrm{min} / \mathrm{kg})$ & $450 \pm 190$ & $213 \pm 118$ & 0.000 \\
\hline TAPSE (mm) & $8.8 \pm 3.0$ & $8.5 \pm 1.5$ & 0.666 \\
\hline $\mathrm{S}^{\prime}(\mathrm{cm} / \mathrm{s})$ & $6.8(6.0-8.2)$ & $5.0(4.0-6.0)$ & $<0.001$ \\
\hline $\mathrm{E}(\mathrm{cm} / \mathrm{s})$ & $67.1 \pm 25.0$ & $49.9 \pm 13.3$ & 0.020 \\
\hline $\mathrm{A}(\mathrm{cm} / \mathrm{s})$ & $57.7 \pm 15.1$ & $57.5 \pm 14.4$ & 0.909 \\
\hline E/A ratio & $0.9(0.7-1.7)$ & $0.8(0.8-1.0)$ & 0.172 \\
\hline $\mathrm{E}^{\prime}(\mathrm{cm} / \mathrm{s})$ & $10.0(7.0-14.3)$ & $6.0(6.0-8.0)$ & $<0.001$ \\
\hline $\mathrm{A}^{\prime}(\mathrm{cm} / \mathrm{s})$ & $10.9 \pm 3.1$ & $8.0 \pm 2.3$ & 0.003 \\
\hline $\mathrm{E} / \mathrm{E}^{\prime}$ ratio & $6.9(4.9-8.1)$ & $7.8(6.1-8.9)$ & 0.110 \\
\hline \multicolumn{4}{|l|}{ Left ventricular function } \\
\hline Stroke volume $(\mathrm{mL})$ & $3.1(2.6-5.7)$ & $4.2(3.4-4.6)$ & 0.144 \\
\hline Cardiac output (L/min) & $0.4(0.4-0.8)$ & $0.5(0.4-0.6)$ & 0.431 \\
\hline Cardiac output adjusted by weight (mL/min/kg) & $134(116-223)$ & $161(127-181)$ & 0.667 \\
\hline Shortening fraction $(\%)$ & $40.5 \pm 7.4$ & $36.8 \pm 6.0$ & 0.066 \\
\hline MAPSE (mm) & $5.4(4.0-7.0)$ & $5.5(5.0-6.0)$ & 0.889 \\
\hline $\mathrm{S}^{\prime}(\mathrm{cm} / \mathrm{s})$ & $4.0(3.2-5.1)$ & $4.0(3.0-5.0)$ & 0.742 \\
\hline $\mathrm{E}(\mathrm{cm} / \mathrm{s})$ & $97.8 \pm 14.5$ & $56.5 \pm 12.9$ & $<0.001$ \\
\hline $\mathrm{A}(\mathrm{cm} / \mathrm{s})$ & $70.5(60.1-84.9)$ & $47.0(43.0-55.0)$ & $<0.001$ \\
\hline E/A ratio & $1.4(1.1-1.7)$ & $1.2(0.9-1.3)$ & 0.022 \\
\hline $\mathrm{E}^{\prime}(\mathrm{cm} / \mathrm{s})$ & $5.2(4.1-6.5)$ & $6.5(5.0-7.0)$ & 0.357 \\
\hline $\mathrm{A}^{\prime}(\mathrm{cm} / \mathrm{s})$ & $5.1 \pm 2.6$ & $6.3 \pm 2.2$ & 0.048 \\
\hline $\mathrm{E} / \mathrm{E}^{\prime}$ ratio & $16.8(12.7-25.0)$ & $9.6(7.0-11.6)$ & $<0.001$ \\
\hline
\end{tabular}

Data are given as mean \pm SD or median (interquartile range). A, ventricular inflow peak velocity in atrial contraction; $\mathrm{A}^{\prime}$, peak myocardial velocity in atrial contraction; E, ventricular inflow peak velocity in early diastole; $\mathrm{E}^{\prime}$, peak myocardial velocity in early diastole; MAPSE, mitral annular plane systolic excursion; S', peak systolic myocardial velocity; TAPSE, tricuspid annular plane systolic excursion.

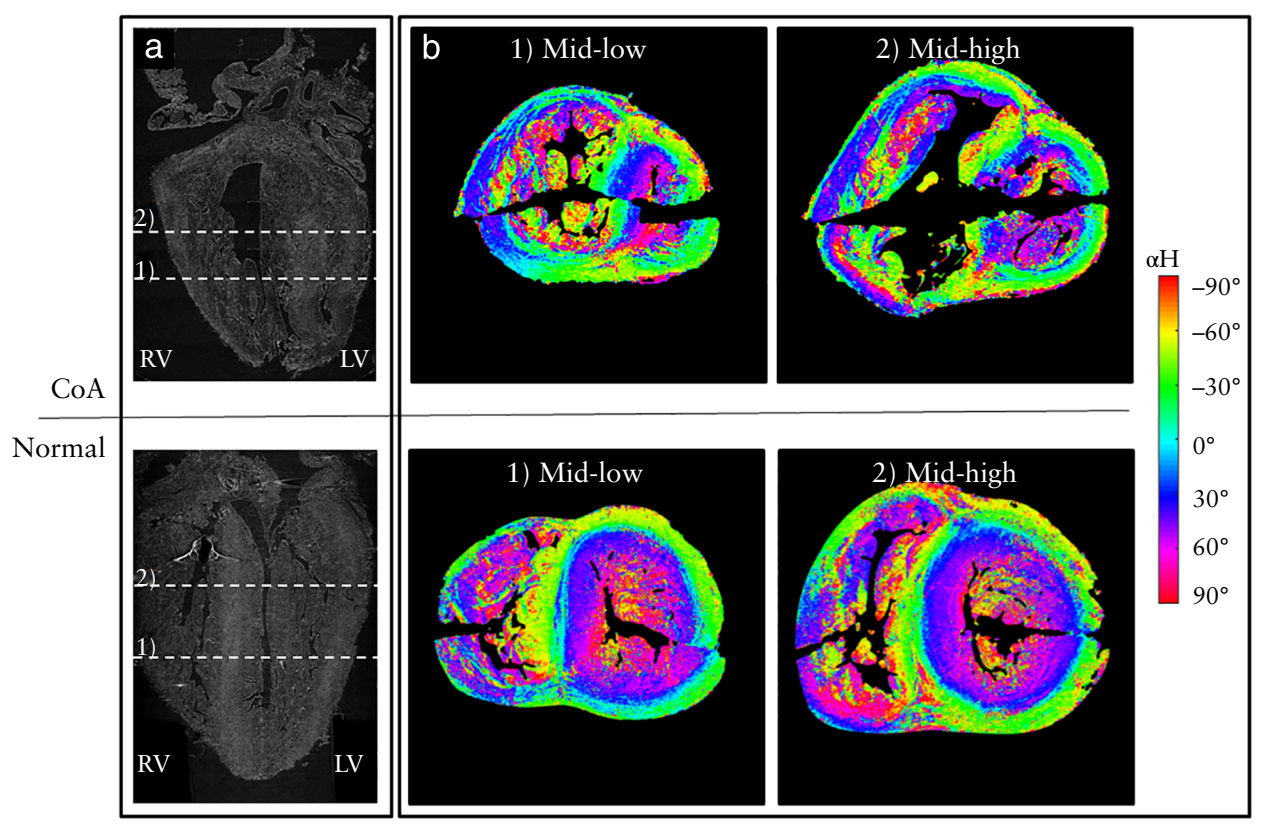

Figure 3 Synchrotron radiation-based X-ray phase-contrast microcomputed tomography (X-PCI) images of heart of fetus with aortic coarctation (CoA) (top) and of normal fetal heart (bottom), at 19 weeks' gestation, showing similar fiber orientation pattern. (a) Virtual longitudinal cuts of resliced X-PCI datasets indicating short-axis slices, in which fiber orientation was measured. (b) Helical angle $\left(\alpha_{H}\right)$ in heart of fetus with CoA and in normal heart, in mid-low and mid-high slices. LV, left ventricle; RV, right ventricle. 

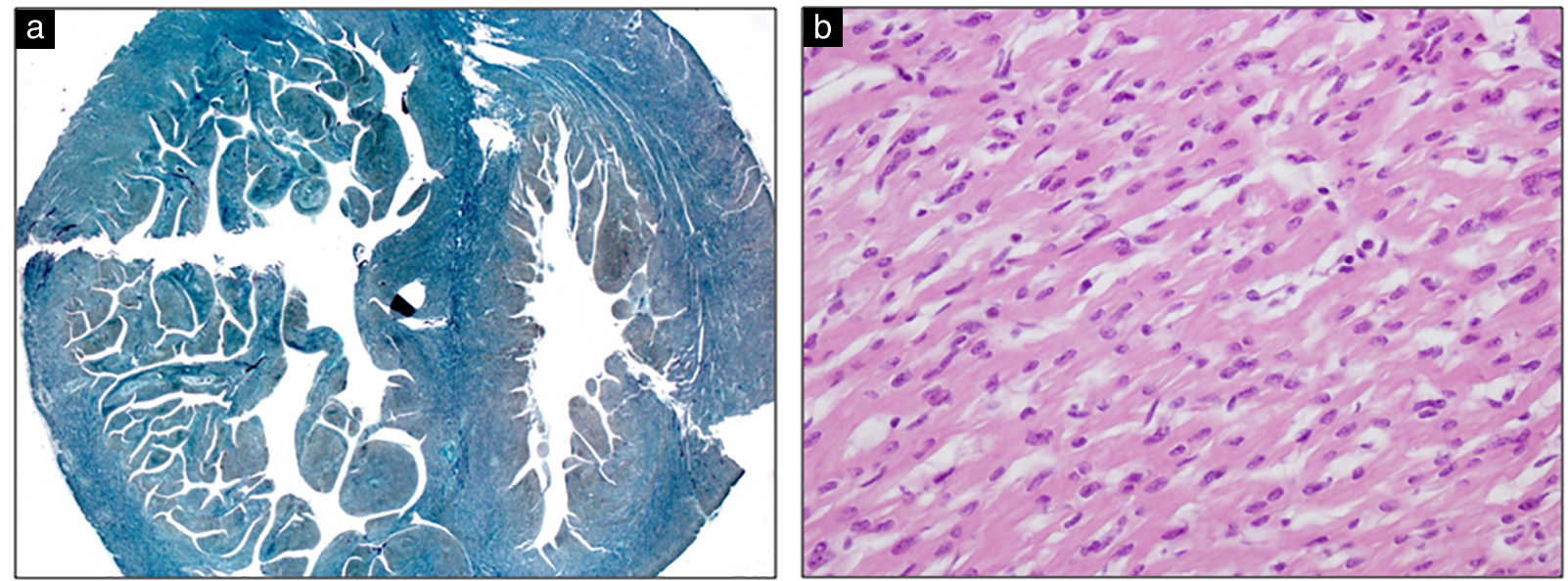

Figure 4 Cardiac histopathology of newborn with aortic coarctation. (a) Low-power microscopic image of ventricular cross-section (Masson trichrome stain). Left ventricle appears narrower than right ventricle with no evident hypertrophy. (b) Hematoxylin-eosin staining of left ventricle showed normal histological appearance of myocardium, with no evidence of myocardial disarray or hypertrophic cardiomyocytes.

volume-loaded, resulting in an overall geometry change and higher filling velocities.

Our work differs from previous studies, which have focused solely on improving prenatal diagnostic accuracy $^{3}$, and provides new insights into the development of the right cardiac dominance in fetuses with CoA and the origin of postnatal LV functional alteration.

\section{Fetal early cardiac remodeling in CoA}

Our findings indicate that cardiac asymmetry in fetal CoA, often described as right-to-left dominance, resulted from significantly smaller left cardiac structures and an abnormally elongated LV shape. The RV was also larger at midventricular level and more globular than in controls (Figure 2). There was no ventricular hypertrophy in either ventricle. Additionally, although limited to one specimen, the high-resolution structural data obtained by X-PCI revealed normal myocyte arrangement in the fetus with CoA (Figure 3). To our knowledge, this is the first study to provide microscopic structural information in the human fetus with CoA, without the artifacts induced by standard histological techniques or contrast agents.

Overall, the elongated shape of the LV, the absence of hypertrophy and of signs of dysfunction are compatible with a functionally normal LV in the setting of decreased LV volume load, further supported by the normal microscopic organization. The volume redistribution towards the RV allows it to provide most of the lower body flow, thus protecting the LV from having to eject volume over the site of CoA, which would result in an additional pressure load.

Thus, the cardiac disproportion present prenatally in fetuses with CoA seems to achieve an optimal ventricular loading balance that limits LV pressure increase, modulated by a reduced right-to-left shunting across the foramen ovale. Animal models support this hypothesis, as right cavities dominance is achieved only by obstructing LV inflow (with an inflated balloon in the left atrium $)^{32}$ and not by direct aortic intervention ${ }^{32,33}$.
Conversely, maternal hyperoxygenation treatment which increases fetal pulmonary venous return and, thus, LV filling, seems to result in LV growth in CoA fetuses ${ }^{34}$. Also, as seen in our study, VSD presence seems to provide further LV filling and results in larger LVs.

Our findings suggest that, despite biventricular remodeling and $\mathrm{CO}$ redistribution, fetuses with $\mathrm{CoA}$ have no significant myocardial dysfunction. Although there are limited data on fetal cardiac function in CoA, a few studies report lower LV strain in fetuses with $\mathrm{CoA}^{4,5,35}$. These studies suggested initially that the decreased LV strain in CoA fetuses was due to an intrinsically abnormal myocardial differentiation ${ }^{4}$. The argument was based on a postmortem histological study of 13 unoperated heart specimens with hypoplastic/borderline LV associated with $\mathrm{CoA}^{4,36}$. However, myocardial histological abnormalities affected only the most severe cases (with multiple left lesions) ${ }^{36}$, limiting causality assumptions between isolated CoA and the abnormalities detected. Moreover, it is known that reduced ventricular loading alone results in lower strain without implying ventricular dysfunction ${ }^{37}$. Additionally, increasing LV loading with maternal hyperoxygenation therapy seems to improve LV strain values in CoA fetuses ${ }^{35}$. However, maternal hyperoxygenation therapy in pregnancies with $\mathrm{CoA}^{34,35}$ is still at an early stage and future studies will help determine its clinical value. Finally, although limited by the sample size, our synchrotron and histopathology data do not support the hypothesis of an intrinsically abnormal myocardium (Figures 3 and 4).

\section{Early postnatal cardiac adaptation in CoA}

Considering our prenatal findings, the LV seems to develop under a low volume load and normal pressure setting. However, the LV seems unprepared for the acute neonatal volume load, as it shows prompt structural remodeling.

Newborns with CoA normalized quickly the LV-CO with an acute LV shape shift towards a globular LV 
and increased filling velocities, but no signs of restriction. These changes accommodate the increased pulmonary venous return and closed foramen ovale and support systemic flow (Tables 4 and 5 and Figure 2).

The only available study in neonates with CoA, prior to surgery and under PGE1 perfusion, reported LV diastolic alterations and decreased myocardial velocities with normal shortening fraction. These results were obtained at a median age of 15 days (i.e. later than in our study), suggesting a progressive maladapted $\mathrm{LV}$ response to pressure increase. Additionally, LV impairment seems to persist after surgery ${ }^{11}$, and up to 12 years after coarctectomy ${ }^{38}$, suggesting that LV remains at increased risk of functional impairment. This risk might also be related to the presence of more generalized vascular dysfunction and impaired arterial reactivity 39,40 and might justify the use of afterload reduction therapy in these children after surgery.

At neonatal assessment, RV normalized its size and shape, however, in the context of a patent arterial duct, the increased RV-SV and RV-CO persisted, with enhanced longitudinal $\mathrm{RV}$ function, as shown by the increased $\mathrm{E}^{\prime}, \mathrm{A}^{\prime}$ and $S^{\prime}$ (Table 5 and Figure 2). Nonetheless, RV functional changes resolve ${ }^{11}$ when volume load normalizes after ductal closure.

In the light of our findings, we hypothesize that the prompt LV remodeling results from acute neonatal volume/pressure overload of a previously functionally normal ventricle.

\section{Limitations}

The relatively small number of fetuses and the high proportion of cases with VSD might limit the interpretation of our results and the power to detect subtle cardiac dysfunction.

Re-evaluation of our results in a larger cohort and using different techniques, including strain analysis, as well as a thorough assessment of flow across the foramen ovale, might provide additional information. Further histological and immunohistochemical analysis of fetal heart specimens with CoA might provide additional information regarding myocardium differentiation, as our analysis was limited to one CoA heart specimen for synchrotron assessment and one for histological assessment.

\section{Conclusions}

Fetuses with CoA showed significant left-to-right volume redistribution, and associated biventricular remodeling, with alterations in size and geometry. These findings suggest unique fetal cardiac remodeling in which the LV stays smaller from the decreased growth stimulus of reduced volume load. This volume redistribution seems to prevent LV pressure increase. Postnatally, the LV is acutely volume-loaded resulting in an overall geometry change, becoming globular, but with preserved systolic function. These results improve our understanding of the evolution of CoA from fetal to neonatal life.

\section{ACKNOWLEDGMENTS}

We thank the study participants for their personal time and commitment to this project.

This study was supported by grants from Hospital Clinic de Barcelona (Ajut Josep Font, Barcelona, Spain); Fundació Daniel Bravo (Barcelona, Spain); la Caixa Foundation (Barcelona, Spain); Cerebra Foundation for the Brain-Injured Child (Carmarthen, UK); AGAUR 2014 SGR grant number 928; Instituto de Salud Carlos III (PI14/00226, PI15/00263, PI15/00130 and INT16/00168), as part of the Plan Nacional de $\mathrm{I}+\mathrm{D}+\mathrm{I}$ and co-funded by ISCIII-Subdirección General de Evaluación; the Fondo Europeo de Desarrollo Regional (FEDER) Otra manera de hacer Europa (Madrid, Spain); and the Spanish Ministry of Economy and Competitiveness (grant TIN2014-52923-R; Maria de Maeztu Units of Excellence Programme - MDM-2015-0502).

We acknowledge the Paul Scherrer Institut, Villigen, Switzerland for provision of synchrotron radiation beamtime at the TOMCAT beamline X02DA of the SLS and part of this work was carried out with the support of the Diamond Light Source (proposal MT11716). No industry funding was used in the development of this work.

\section{REFERENCES}

1. Rosenthal E. Coarctation of the aorta from fetus to adult: curable condition or life long disease process? Heart 2005; 91: 1495-1502.

2. Wren C, Reinhardt Z, Khawaja K. Twenty-year trends in diagnosis of life-threatening neonatal cardiovascular malformations. Arch Dis Child Fetal Neonatal Ed 2008; 93: F33-35.

3. Familiari A, Morlando M, Khalil A, Sonesson S-E, Scala C, Rizzo G, Del Sordo G, Vassallo C, Elena Flacco M, Manzoli L, Lanzone A, Scambia G, Acharya G, D'Antonio F. Risk Factors for Coarctation of the Aorta on Prenatal Ultrasound: A Systematic Review \& Meta-Analysis. Circulation 2017; 135: 772-785.

4. Miranda JO, Hunter L, Tibby S, Sharland G, Miller O, Simpson JM. Myocardial deformation in fetuses with coarctation of the aorta: a case-control study. Ultrasound Obstet Gynecol 2017; 49: 623-629.

5. Germanakis I, Matsui H, Gardiner HM. Myocardial Strain Abnormalities in Fetal Congenital Heart Disease Assessed by Speckle Tracking Echocardiography. Fetal Diagn Ther 2012; 32: 123-130.

6. Cohn JN, Ferrari R, Sharpe N. Cardiac remodeling-concepts and clinical implications: a consensus paper from an international forum on cardiac remodeling. J Am Coll Cardiol 2000; 35: 569-582.

7. Barker DJP. Adult consequences of fetal growth restriction. Clin Obstet Gynecol 2006; 49: 270-283.

8. Crispi F, Bijnens B, Figueras F, Bartrons J, Eixarch E, Le Noble F, Ahmed A, Gratacós E. Fetal Growth Restriction Results in Remodeled and Less Efficient Hearts in Children. Circulation 2010; 121: 2427-2436.

9. García-Otero L, López M, Gómez O, Goncé A, Bennasar M, Martínez JM, Valenzuela-Alcaraz B, Rodriguez-López M, Sitges M, Loncà M, Bijnens B, Crispi F, Gratacós E. Zidovudine treatment in HIV-infected pregnant women is associated with fetal cardiac remodelling. AIDS 2016; 30:1393-1401.

10. Guirado L, Crispi F, Masoller N, Bennasar M, Marimon E, Carretero J, Gratacós E, Martínez J, Friedberg M, Gómez O. Biventricular impact of mild to moderate pulmonary valve stenosis in fetal life. Ultrasound Obstet Gynecol 2017; 51:349-356.

11. Klitsie LM, Roest AAW, Kuipers IM, Van der Hulst AE, Hazekamp MG, Blom NA, Ten Harkel ADJ. Enhanced Characterization of Ventricular Performance After Coarctation Repair in Neonates and Young Children. Ann Thorac Surg 2013; 96: 629-636.

12. Lam Y-Y, Kaya MG, Li W, Gatzoulis MA, Henein MY. Effect of Chronic Afterload Increase on Left Ventricular Myocardial Function in Patients With Congenital Left-Sided Obstructive Lesions. Am J Cardiol 2007; 99: 1582-1587.

13. Brili S, Tousoulis D, Antoniades C, Aggeli C, Roubelakis A, Papathanasiu S, Stefanadis C. Evidence of vascular dysfunction in young patients with successfully repaired coarctation of aorta. Atherosclerosis 2005; 182: 97-103.

14. Gonzalez-Tendero A, Zhang C, Balicevic V, Cárdenes R, Loncaric S, Butakoff C, Paun B, Bonnin A, Garcia-Cañadilla P, Muñoz-Moreno E, Gratacós E, Crispi F, Bijnens B. Whole heart detailed and quantitative anatomy, myofibre structure and vasculature from X-ray phase-contrast synchrotron radiation-based micro computed tomography. Eur Heart J Cardiovasc Imaging 2017; 18: 732-741. 
15. Garcia-Cañadilla P, Dejea H, Bonnin A, Balicevic V, Loncaric S, Zhang C, Butakoff C, Aguado-Sierra J, Vázquez M, Jackson LH, Stuckey DJ, Rau C, Stampanoni M, Bijnens B, Cook AC. Complex Congenital Heart Disease Associated With Disordered Myocardial Architecture in a Midtrimester Human Fetus. Circ Cardiovasc Imaging 2018; 11: e007753.

16. Robinson HP, Sweet EM, Adam AH. The accuracy of radiological estimates of gestational age using early fetal crown-rump length measurements by ultrasound as a basis for comparison. Br J Obstet Gynaecol 1979; 86: 525-528.

17. Carvalho J, Allan L, Chaoui R, Copel J, DeVore G, Hecher K, Lee W, Munoz H, Paladini D, Tutschek B, Yagel S. ISUOG Practice Guidelines (updated): sonographic screening examination of the fetal heart. Ultrasound Obstet Gynecol 2013; 41: $348-359$.

18. Bhide A, Acharya G, Bilardo CM, Brezinka C, Cafici D, Hernandez-Andrade E, Kalache K, Kingdom J, Kiserud T, Lee W, Lees C, Leung KY, Malinger G, Mari G, Prefumo F, Sepulveda W, Trudinger B. ISUOG practice guidelines: use of Doppler ultrasonography in obstetrics. Ultrasound Obstet Gynecol 2013; 41: 233-239.

19. Hadlock FP, Harrist RB, Shah YP, King DE, Park SK, Sharman RS. Estimating fetal age using multiple parameters: A prospective evaluation in a racially mixed population. Am J Obstet Gynecol 1987; 156: 955-957.

20. Figueras F, Meler E, Iraola A, Eixarch E, Coll O, Figueras J, Francis A, Gratacós E, Gardosi J. Customized birthweight standards for a Spanish population. Eur J Obstet Gynecol Reprod Biol 2008; 136: 20-24.

21. García-Otero L, Gómez O, Rodriguez-López M, Torres X, Soveral I, Sepúlveda-Martínez Á, Guirado L, Valenzuela-Alcaraz B, López M, Martínez JM, Gratacós E, Crispi F. Nomograms of Fetal Cardiac Dimensions at 18-41 Weeks of Gestation. Fetal Diagn Ther 2020; 47: 387-398.

22. Paladini D, Chita SK, Allan LD. Prenatal measurement of cardiothoracic ratio in evaluation of heart disease. Arch Dis Child 1990; 65: 20-23.

23. Schneider C, McCrindle BW, Carvalho JS, Hornberger LK, McCarthy KP, Daubeney PEF. Development of $Z$-scores for fetal cardiac dimensions from echocardiography. Ultrasound Obstet Gynecol 2005; 26: 599-605.

24. DeVore GR, Siassi B, Platt LD. Fetal echocardiography. IV. M-mode assessment of ventricular size and contractility during the second and third trimesters of pregnancy in the normal fetus. Am J Obstet Gynecol 1984; 150: 981-988.

25. Crispi F, Valenzuela-Alcaraz B, Cruz-Lemini M, Gratacós E. Ultrasound assessment of fetal cardiac function. Australas J Ultrasound Med 2013; 16: 158-167.

26. Kiserud T, Ebbing C, Kessler J, Rasmussen S. Fetal cardiac output, distribution to the placenta and impact of placental compromise. Ultrasound Obstet Gynecol 2006; 28: $126-136$.

27. Cruz-Lemini M, Crispi F, Valenzuela-Alcaraz B, Figueras F, Sitges M, Gómez O, Bijnens B, Gratacós E. Value of annular M-mode displacement $v s$ tissue Doppler velocities to assess cardiac function in intrauterine growth restriction. Ultrasound Obstet Gynecol 2013; 42: 175-181.
28. Comas M, Crispi F, Gómez O, Puerto B, Figueras F, Gratacós E. Gestational age- and estimated fetal weight-adjusted reference ranges for myocardial tissue Doppler indices at 24-41 weeks' gestation. Ultrasound Obstet Gynecol 2011; 37: $57-64$.

29. Hernandez-Andrade E, Benavides-Serralde JA, Cruz-Martinez R, Welsh A, Mancilla-Ramirez J. Evaluation of Conventional Doppler Fetal Cardiac Function Parameters: E/A Ratios, Outflow Tracts, and Myocardial Performance Index. Fetal Diagn Ther 2012; 32: 22-29.

30. Lopez L, Colan SD, Frommelt PC, Ensing GJ, Kendall K, Younoszai AK, Lai WW, Geva T. Recommendations for Quantification Methods During the Performance of a Pediatric Echocardiogram: A Report From the Pediatric Measurements Writing Group of the American Society of Echocardiography Pediatric and Congenital Heart Disease Council. J Am Soc Echocardiogr 2010; 23: 465-495.

31. Anderson RH, Ho SY, Redmann K, Sanchez-Quintana D, Lunkenheimer PP. The anatomical arrangement of the myocardial cells making up the ventricular mass. Eur J CardioThoracic Surg 2005; 28: 517-525.

32. Fishman NH, Hof RB, Rudolph AM, Heymann MA. Models of congenital heart disease in fetal lambs. Circulation 1978; 58: 354-364.

33. Samson F, Bonnet N, Heimburger M, Rücker-Martin C, Levitsky DO, Mazmanian GM, Mercadier J-J, Serraf A. Left Ventricular Alterations in a Model of Fetal Left Ventricular Overload. Pediatr Res 2000; 48: 43-49.

34. Zeng S, Zhou J, Peng Q, Deng W, Zhang M, Zhao Y, Wang T, Zhou Q Sustained maternal hyperoxygenation improves aortic arch dimensions in fetuses with coarctation. Sci Rep 2016; 6: 39304

35. Zeng S, Zhou J, Peng Q, Deng W, Zang M, Wang T, Zhou Q. Sustained Chronic Maternal Hyperoxygenation Increases Myocardial Deformation in Fetuses with a Small Aortic Isthmus at Risk for Coarctation. J Am Soc Echocardiogr 2017; 30 992-1000.

36. Mahtab EAF, Gittenberger-de Groot AC, Vicente-Steijn R, Lie-Venema H, Rijlaarsdam MEB, Hazekamp MG, Bartelings MM. Disturbed myocardial connexin 43 and $\mathrm{N}$-cadherin expressions in hypoplastic left heart syndrome and borderline left ventricle. J Thorac Cardiovasc Surg 2012; 144: 1315-1322.

37. Bijnens BH, Cikes M, Claus P, Sutherland GR. Velocity and deformation imaging for the assessment of myocardial dysfunction. Eur I Echocardiogr 2008; 10: 216-226.

38. Florianczyk T, Werner B. Assessment of left ventricular diastolic function in children after successful repair of aortic coarctation. Clin Res Cardiol 2011; 100: 493-499.

39. Gardiner HM, Celermajer DS, Sorensen KE, Georgakopoulos D, Robinson J, Thomas O, Deanfield JE. Arterial reactivity is significantly impaired in normotensive young adults after successful repair of aortic coarctation in childhood. Circulation 1994; 89: 1745-1750.

40. de Divitiis M, Pilla C, Kattenhorn M, Zadinello M, Donald A, Leeson P, Wallace S, Redington A, Deanfield JE. Vascular dysfunction after repair of coarctation of the aorta: impact of early surgery. Circulation 2001; 104 (12 Suppl 1): I165-170.

\section{SUPPORTING INFORMATION ON THE INTERNET}

The following supporting information may be found in the online version of this article:

Appendix S1 Data acquisition using synchrotron radiation-based phase-contrast computed tomography Table S1 Perinatal characteristics in fetuses with aortic coarctation, according to presence of ventricular septal defect (VSD)

Table S2 Fetal echocardiographic morphometric findings in cases with aortic coarctation, according to presence of ventricular septal defect (VSD)

Table S3 Fetal functional echocardiographic findings in cases with aortic coarctation, according to presence of ventricular septal defect (VSD)

Table S4 Neonatal echocardiographic morphometric findings in infants with aortic coarctation, according to presence of ventricular septal defect (VSD)

Table S5 Neonatal echocardiographic functional findings in infants with aortic coarctation, according to presence of ventricular septal defect (VSD) 